\title{
Biomarkers in Enteropathic Arthritis
}

\section{Luis Arturo Gutiérrez-Gonzalez ${ }^{1 *}$, Eillen Macias², Freddy Herrera-Vivas ${ }^{3}$, Franz Otaiza ${ }^{4}$, Juan Carlos Gonzalez Duran ${ }^{4}$ and Guillermo Veitia ${ }^{5}$}

\author{
${ }^{1}$ Internal Medicine and Rheumatology Unit (UMIR). Clínica El Avila, Altamira, Caracas, Venezuela \\ ${ }^{2}$ Rheumatology Clinic. National Center for Rheumatic Diseases (CNER). Hospital Universitario de \\ Caracas. Caracas, Venezuela \\ ${ }^{3}$ Rheumatology Clinic, San Antonio de Los Altos, Gran Caracas, Venezuela \\ ${ }^{4}$ Gastroenterology Service, Hospital Universitario de Caracas, Carcas, Venezuela \\ ${ }^{5}$ Gastroenterology Service. Hospital Dr. Jose María vargas, Caracas, Venezuela
}

\section{Abstract}

Inflammatory Bowel Disease (IBD)-associated arthritis is called Enteropathic Arthritis (EA) which is classified among the group of Spondyloarthritis $(\mathrm{SpA})$, because its presentation is variable. The current trend is to classify them as autoinflammatory rather than autoimmune diseases, since no antibodies have yet been identified. The study of biomarkers (BM) will help us with early identification and hence, to provide treatment in the early stages, prior to radiographic progression, which will enable prompt identification of the disease phenotype. 42 patients diagnosed with IBD were included, of which $48 \%$ were females; the mean age of the study group was $48.12 \pm 5.02(95 \% \mathrm{Cl})$. The average time of evolution of disease was $37.57 \pm 14.28$ months; most patients referred to the rheumatologist had a diagnosis of ulcerative colitis $(83 \%)$. According to our analysis, we were able to determine that the three most significant variables influencing the development of sacroiliitis were: Lactoferrin, ANCA and HLA B27 $(p<0.5)$. The variable that can be ruled out because of its almost neglectable contribution was fecal calprotectin.

\section{More Information}

*Address for Correspondence: Luis Arturo Gutiérrez-Gonzalez, Internal Medicine and Rheumatology Unit (UMIR). Clínica El Avila, Altamira, Caracas, Venezuela,

Tel: +58212-276.1583;+58212-2761582;

Email: umircaracas@yahoo.es

Submitted: 25 May 2020

Approved: 03 June 2020

Published: 04 June 2020

How to cite this article: Gutiérrez-Gonzalez LA, Macias E, Herrera-Vivas F, Otaiza F, Duran JCG et al. Biomarkers in Enteropathic Arthritis. Ann Clin Gastroenterol Hepatol. 2020; 4: 039-044.

DOI: 10.29328/journal.acgh.1001021

ORCiD: orcid.org/0000-0003-0264-9738

Copyright: @ 2020 Gutiérrez-Gonzalez LA, et al. This is an open access article distributed under the Creative Commons Attribution License, which permits unrestricted use, distribution, and reproduction in any medium, provided the original work is properly cited.

Keywords: Biomarkers; Spondyloarthritis; Inflammatory Bowel Disease; ASCA; ANCA; HLAB-27

A) Check for updates

OPEN ACCESS

\section{Introduction}

The tests that link serological biomarkers (BM) to the behavior and phenotype of inflammatory bowel disease (IBD) have grown significantly over the last few years; however, there are notable differences among the various populations, particularly when dealing with miscegenation, which is the standard in Latin America [1,2].

Until now, the anti-Saccharomyces cerevisiae antibodies (ASCA) and the perinuclear anti-neutrophil cytoplasmic antibodies (p-ANCA) are the best BM studied in IBD $[3,4]$. The diagnostic certainty of the independent study of these BM has been outmatched by the combination of its results, resulting in improved differentiation between Crohn's Disease (CD) and ulcerative colitis (UC) $[5,6]$. The ASCA+/pANCA- phenotype is characteristic of CD, whilst the ASCA/p-ANCA+ phenotype is characteristic of UC [5-8]. The atypical pattern of the p-ANCA (x-ANCA) has been recently recognized with growing interest, considering it may be a useful tool to be able to differentiate the various forms of IBD [9]. However, the association of BM in Enteropathic Arthropathies (EA) is uncertain, since the various study and control groups for these types of diseases (ACR/EULAR/
Spartan/ASAS/ESSG) have only agreed on classifying them as another type of Spondyloarthritis ( $\mathrm{SpA}$ ); some include celiac disease and arthritis associated with bariatric surgery, and others rule out Whipple disease and collagenous colitis $[5,10]$.

To further complicate matters in EA, there are three forms of presentation: peripheral enteroarthritis (Type 1), axial enteroarthritis (Type 2), and a so called "without arthritis" (Type 3) [11]. The latter presents with arthralgias, enthesitis, peritendinitis, and hypertrophic osteoarthropathy $[5,12,13]$. Type 1 is divided into pauciarticular and polyarticular. Type 2 in inflammatory bowel disease behaves as idiopathic ankylosing spondylitis or as an asymptomatic sacroiliitis [14]. Though, different from what usually happens in peripheral arthritis, the axial presentation evolves independently from IBD and the clinical manifestations are unrelated with the remission periods and exacerbation, or with the localization or extension of the intestinal disease $[15,16]$. Moreover, the onset of axial symptoms is frequently independent and tends to precede the gut disease by several years $[17,18]$.

The prevalence of IBD in patients with SpA has been estimated at around 5 to $10 \%$, but almost $50 \%$ of the patients 
with SpA present with subclinical inflammation. From the viewpoint of IBD, $3 \%$ of patients experience concomitant EA and $13 \%$ have peripheral SpA, but the radiographic sacroiliitis - whether symptomatic or subclinical - may compromise half of the patients with IBD $[5,20,21]$.

\section{Patients and methods}

42 patients referred from the Gastroenterology department, with a diagnosis of ulcerative colitis (UC) and Crohn's disease (CD) were included; these patients had no previous history of SpA and were subject to the criteria for EA according to the ESSG (European Spondyloarthropathy Study Group), in addition to undergoing plain X-rays and MRI, pursuant to the ASAS/OMERACT (Outcome Measures in Rheumatology Network) protocol, under the responsibility of the radiology service of our hospital, by two expert radiologists. Blood samples were drawn for routine laboratory testing, including $\mathrm{CBC}$, blood chemistry panel, in addition to acute phase reactants (ESR/CRP), as well as a blood sample for biomarkers: ANA, HLA B27, ASCA IgG, ASCA IgA and ANCA and a fecal sample to measure lactoferrin and fecal calprotectin.

Both groups of patients were assessed in terms of their clinical characteristics, family history of autoimmunity, extraintestinal characteristics including skin, ocular, cardiovascular, and pulmonary. The study was approved by the HUC/UCV Bioethics Committee prior to drawing the blood samples and completing the patient's form and a copy of the informed consent was delivered and explained to the patient. The ANA, ANCA and ESR tests were conducted in our rheumatology laboratory on the first floor of our clinic; the HLAB27, ASCA IgA, ASCA IgG tests were conducted at the UCV immunology institute. Fecal calprotectin and lactoferrin tests were conducted by a private laboratory (InmunoXXI) and were paid from the study fund of our study group (GRUVES) and in some cases by Abbvie ${ }^{\circledR}$ Laboratories.

The patients diagnosed with EA were then classified based on their severity, based on the collection of clinical and laboratory data, imaging studies as well as a history of joint replacement prosthesis, and if the patient had undergone any arthrodesis, laparotomies and/or hemicolectomy procedures. Activity and severity information was collected via DAS28, BASDAI and BASFI, as well as information about the type of treatment received: DC- ART, glucocorticoids, Anti-TNF therapy, NSAIDs.

\section{Statistical analysis}

The data obtained from the research were uploaded and processed using the IBM SPSS 23.0 software in order to:

a) Obtain the basic statistics of the most relevant variables

b) Determine the relationship among the various variables by obtaining the matrix containing Spearman's correlation coefficients c) Do a logistic regression analysis to identify the most relevant variables in predicting the presence of the disease.

\section{Results}

\section{a) Descriptive Statistics}

A total of 42 patients diagnosed with IBD were included, with $48 \%$ females and a $95 \%$ confidence interval for the mean age of the study group of $48.12 \pm 5.02$, while the $95 \% \mathrm{CI}$ for the mean time of disease evolution was $37.57 \pm 14.28$. Most of the patients referred to rheumatology had a diagnosis of UC (35 patients), 90\% were receiving Anti-TNF- $\alpha$ treatment, over $60 \%$ received glucocorticoids, and half of them received sulfasalazine. Only 8 patients presented with HLA B27 (+) and the fecal calprotectin was negative in all patients (Table 1).

ANA was positive in 17 patients ( $40 \%$ ), $53 \%$ of the patients were Type 2, 19\% (8 patients) Type 3 and the rest were EA type $1(28 \%)$. Both ANCA and ASCA IgG were present in only 5 patients in the trial. BASDAI was only administered to the 8 type 2 patients, resulting in a value of $3.54 \pm 2.3$, while only 5 of them had a BASDAI $\geq 4.0$. DAS $286.34 \pm 1.12$. The majority of the patients with Type 2 EA presented with HLA B27 (75\%; $p<0.005)$. Two patients who after gastric bypass surgery developed oligoarticular pathology with inflammatory axial pain and the presence of HLA B27 were included (Table 2).

All patients underwent imaging studies to screen for sacroiliitis; conventional X-rays with oblique and Fergunson projections were ordered, in addition MRI according to the ASAS/OMERACT protocol (Table 3), identifying 74\% with active sacroiliitis and bone edema following STIR. Under conventional radiology, 23\% presented with bilateral but asymmetric grade III sacroiliitis, $37 \%$ Grade II sacroiliitis, and $17 \%$ presented with anchyloses (Grade IV).

\section{b) Spearman's correlation}

Spearman's correlations for: ESR, CRP, ANA, ASCA, Lactoferrin, Calprotectin, and the significance of the test: Ho: correlation coefficient $=0$, vs. H1: correlation coefficient $\neq 0$ are shown in table 4.

\section{c) Logistic Regression}

The logistic regression taking $Y$ as a variable: the presence of sacroiliitis and as explanatory variables: ANA, ANCA, ASCA, HLA B27, Calprotectin. Lactoferrin gave in the Hosmer Lemeshow test a $p$-value of 0.779 , implying that the good model adjustment hypothesis is not ruled out (Table 5).

Radiographic progression model considering the following variables: HLA B27/lactoferrin was 52.4 5\%, for the variables lactoferrin/ANCA $52.4 \%$, but the triplet: Lactoferrin/ANCA/HLA B27 was $66.7 \%(p<0.5)$. However, the Calprotectin variable value was $1.1 \%(p>0.9)$. 
Table 1: Characteristics and distribution of patients referred to rheumatology.

\begin{tabular}{|c|c|}
\hline Gen & $\begin{array}{c}\text { Female:20 (48\%) } \\
\text { Male:22 (52\%) }\end{array}$ \\
\hline Age, year & $48.12 \pm 5.02$ \\
\hline Diagnoses & $\begin{array}{c}\text { URC35 }(83 \% \\
\text { CD5 }(12 \%) \\
\text { Other2 }(5 \%)\end{array}$ \\
\hline Esr & $43.86 \pm 9.36$ \\
\hline Crp & $24.56 \pm 6.86$ \\
\hline Evolution of the disease (months) & $37.57 \pm 14.38$ \\
\hline \multirow[t]{6}{*}{ Treatment } & Glucocorticoids 29 (69\%) \\
\hline & Sulfasalazine $21(50 \%)$ \\
\hline & Azathioprine 11 (26\%) \\
\hline & Methotrexate 12 (29\%) \\
\hline & Anti TNF 38 (90\%) \\
\hline & Others $4(10 \%)$ \\
\hline Sacroiliitis & $31(74 \%)$ \\
\hline Ana & $17(40 \%)$ \\
\hline Anca & $5(12 \%)$ \\
\hline Asca iga & $13(31 \%)$ \\
\hline Asca igg & $5(12 \%)$ \\
\hline Lactoferrin & $6(14 \%)$ \\
\hline Calprotectin & $92.7 \pm 28.3$ \\
\hline Hla b27 & $8(19 \%)$ \\
\hline
\end{tabular}

*URC: Ulcerative Rectocolitis; CD: Crohn's Disease; ESR: Erythrocyte Sedimentation Rate; By Westergren (Positive > 20 mm In Females And > 15 In Males); CRP: C-Reactive Protein (Positive > 6 Mg/DI); Anti-Tnf A Anti-Tumor Necrosis Factor Alpha Biologics; Other Drugs Such as Non-Steroid Anti Inflammatory Drugs/Cyclosporin; Ana Antinuclear Antibodies Measured With Hep-2; Anca Anti-Neutrophil Cytoplasmic Antibodies (Measured Through Indirect Immunofluorescence); Asca Anti-Saccharomyces Cerevisiae Antibodies (Measured With Elisa); Fecal Lactoferrin Measured Through Latex Agglutination; Fecal Calprotectin Measured With Elisa; Hla B27 Histocompatibility B27 Antigen (Measured With Flow Cytometry).

Table 2: EA type distribution according to gender and biomarker.

\begin{tabular}{|c|c|c|c|c|}
\hline & Type 1 & Type 2 & Type 3 & $\boldsymbol{p}<\mathbf{0 . 0 5}$ \\
\hline Gender F/M (\%) & $34 / 31$ & $9 / 67$ & $45 / 2$ & \\
\hline ANA & 4 & 5 & 8 & 0.789 \\
\hline ASCA IgA & 4 & 4 & 5 & 0.345 \\
\hline ASCA IgG & 2 & 1 & 2 & 0.125 \\
\hline ANCA p & 1 & 3 & - & 0.283 \\
\hline ANCA c & - & 1 & - & 0.987 \\
\hline HLA B27 & - & 7 & 1 & $0.001^{*}$ \\
\hline Lactoferrin & 1 & 2 & 3 & \\
\hline Calprotectin & - & - & - & - \\
\hline
\end{tabular}

Table 3: Distribution of patients with Sacroiliitis.

\begin{tabular}{|l|l|c|c|c|}
\hline \multirow{3}{*}{ Diagnosis } & \multicolumn{5}{|c|}{ Sacroilitis } \\
\hline \multirow{3}{*}{} & URC & $16(38.1 \%)$ & $19(45.24 \%)$ & 35 \\
\cline { 2 - 5 } & EC & $4(9.52 \%)$ & $1(2.38 \%)$ & 5 \\
\cline { 2 - 5 } & Other & $1(2.38 \%)$ & $1(2.38 \%)$ & 2 \\
\hline & Total & 21 & 21 & $42^{*}$ \\
\hline
\end{tabular}

The elevation of acute phase reactants (ESR/CRP) as a positive predictor of the progression of sacroiliitis in type 1 and type 3 EA resulted in an OR of 3.65 and 5.08. Respectively $(p<0.05)$; however, for type 2 , the odds ratio [OR] was 6.29 $(p<0.001)$, provided lactoferrin is present (data not shown).

The presence of syndesmophytes was independently associated with spinal radiographic progression and an odds ratio [OR] of $0.810(p<0.001)$, elevated levels of acute phase reactants (for the Erythrocyte Sedimentation Rate, OR of $0.810, p<0.9$; for $\mathrm{C}$ - reactive protein level OR of 1.948, $p<$ 0.9 ) and lactoferrin (OR 0.267. $p=0.012$ ) (Table 6).

\section{Discussion}

The number tests for the association between biomarkers and the behavior and phenotype of the inflammatory bowel disease (IBD) has significantly increased over the past few years; however, their role as predictors for EA has not yet been established, and even less so in mestizo populations such as the Venezuelan people [22].

Our analysis indicates that the most relevant variables contributing to the explanation of sacroiliitis are: Lactoferrin, ANCA and HLA B27 ( $p<0.09)$. A variable that may be excluded because of its almost insignificant contribution is fecal Calprotectin. One of the frequent diagnostic difficulties is that of differentiating between mild to moderate cases, with varying underlaying causes for intestinal inflammatory processes of those that do not present with an organic disease, although in our study, most patients presented with high DAS28 and BASDAI scores.

There are conflicting opinions with regards to the vulnerability of biomarkers and the use of drugs (measurements in treated patients) [23-27], considering that all of our patients are already being treated with some type of drug, which may influence the measurement of the biomarker. Kohlo, et al. [28], showed that the use of glucocorticoids did not influence the calprotectin values; however, one year later, the Spanish work by Bonnin, et al. [29] found that the levels of Calprotectin decreased following the use of corticosteroids; in our study, most patients (69\%) were receiving glucocorticoid therapy. 


\begin{tabular}{|c|c|c|c|c|c|c|c|c|c|c|}
\hline & & & ESR & CRP & ANA & ANCA & LACTOFERRIN & CALPROTECTIN & ASCAlgA & ASCAlgG \\
\hline \multirow{17}{*}{ Spearman's Rho } & \multirow{2}{*}{$\begin{array}{c}\text { ESR } \\
(n\end{array}$} & Coefficient & 1.000 & .157 & -.080 & .021 & -.113 & .005 & -.054 & -.025 \\
\hline & & Sig. (Bil) & & .321 & .613 & .894 & .478 & .973 & .733 & .876 \\
\hline & \multirow[b]{2}{*}{ PCR } & Coefficient & .157 & 1.000 & -.072 & -.167 & .095 & .079 & .123 & .091 \\
\hline & & Sig. (Bil) & .321 & & .650 & .291 & .548 & .618 & .438 & .567 \\
\hline & \multirow[b]{2}{*}{ ANA } & Coefficient & -.080 & -.072 & 1.000 & .146 & -.059 & .080 & .070 & -.028 \\
\hline & & Sig. (Bil) & .613 & .650 & & .355 & .709 & .614 & .659 & .860 \\
\hline & \multirow[b]{2}{*}{ ANCA } & Coefficient & .021 & -.167 & .146 & 1.000 & .060 & .055 & .270 & -.049 \\
\hline & & Sig.(Bil) & .894 & .291 & .355 & & .706 & .731 & .084 & .760 \\
\hline & \multirow[b]{2}{*}{ LACTOFERRINA } & Coefficient & -.113 & .095 & -.059 & .060 & 1.000 & .253 & -.160 & $-.396^{* *}$ \\
\hline & & Sig.(Bil) & .478 & .548 & .709 & .706 & & .106 & .311 & $.009^{*}$ \\
\hline & \multirow[b]{2}{*}{ CALPROTECTINA } & Coefficient & .005 & .079 & .080 & .055 & .253 & 1.000 & -.248 & -.078 \\
\hline & & Sig. (Bil) & .973 & .618 & .614 & .731 & .106 & . & .114 & .623 \\
\hline & \multirow[b]{2}{*}{ ASCA IgA } & Coefficient & -.054 & .123 & .070 & .270 & -.160 & -.248 & 1.000 & .097 \\
\hline & & Sig.(Bil) & .733 & .438 & .659 & .084 & .311 & .114 & . & .541 \\
\hline & \multirow{3}{*}{$\begin{array}{c}\text { ASCA } \\
\lg G\end{array}$} & Coefficient & -.025 & .091 & -.028 & -.049 & $-.396^{*+}$ & -.078 & .097 & 1.000 \\
\hline & & Sig. (bil) & .876 & .567 & .860 & .760 & .009 & .623 & .541 & . \\
\hline & & $\mathrm{N}$ & 42 & 42 & 42 & 42 & 42 & 42 & 42 & 42 \\
\hline
\end{tabular}

**The correlation is significant at the 0.01 level (bilateral).

\begin{tabular}{|c|c|c|c|c|c|}
\hline Step & Chi square & $\mathrm{gl}$ & Sig. & & \\
\hline 1 & 4.794 & 8 & .779 & & \\
\hline & \multirow{3}{*}{\multicolumn{2}{|c|}{ Observed }} & \multicolumn{3}{|c|}{ Forecasted } \\
\hline & & & \multicolumn{2}{|c|}{ Sacroiliitis } & \multirow{2}{*}{ Correct percentage } \\
\hline & & & .00 & 1.00 & \\
\hline \multirow[t]{3}{*}{ Step 1} & \multirow{2}{*}{ Sacroiliitis } & .00 & 11 & 10 & 52.4 \\
\hline & & 1.00 & 7 & 14 & 66.7 \\
\hline & \multicolumn{2}{|c|}{ Overall percentage } & & & 59.5 \\
\hline
\end{tabular}

Table 6: Radiographic progression assessed through the presence of syndesmophytes.

\begin{tabular}{|c|c|c|c|c|c|c|}
\hline & B & E.T. & Wald & gl & Sig. & Exp(B) \\
\hline ESR & -0.211 & 0.674 & 0.098 & 1 & 0.755 & 0.81 \\
\hline CRP & 0.667 & 1.049 & 0.404 & 1 & 0.525 & 1.948 \\
\hline ASCA IgA & -0.027 & 0.051 & 0.285 & 1 & 0.593 & 0.973 \\
\hline HLA B27 & -0.508 & 0.889 & 0.327 & 1 & 0.568 & 0.602 \\
\hline Calprotectin & 0.003 & $.004^{*}$ & 0.71 & 1 & 0.399 & 1.003 \\
\hline Lactoferrin & -1.321 & 1.159 & 1.299 & 1 & 0.254 & 0.267 \\
\hline Syndesmophyte & 0.167 & 0.648 & 0.067 & 1 & 0.796 & 1.182 \\
\hline
\end{tabular}

In the H-L model (Table 7) you may appreciate that the rise in ANCA from 0 to 1, with the rest of the variables remaining constant, results in a 1.948 fold increase in the odds ratio; however, the increase in HLA B27 from 0 to 1, with the other variables remaining constant, results in a drop in the odds ratio of 0.602 for Lactoferrin, an increase in Lactoferrin from 0 to 1 , with the other variables remaining constant, resulting in a drop in the odds ratio of 0.267 .

We now have markers available derived from several gut microbial species (antibodies against porin type C from the Escherichia coli outer membrane, antibodies against Pseudomonas fluorescens-associated I2 sequence, antibodies against flagellin, antibodies against chitobioside, laminaribioside, and mannobioside carbohydrates) which allow for new ways of classifying patients with IBD [30]. These markers may act as prognostic and behavioral indicators of the disease; furthermore, like in the case of ASCA and ANCA, the combined results lead to improved diagnostic certainty [31-34].

It should be highlighted however that correlation coefficients measure the relationships between the variables considered, keeping the other variables constant and should not be interpreted vis a third variable. Hence, in our prediction model, the variables Lactoferrin and ASCA IgG are considered a worse prognosis for the development of sacroiliitis.

An Italian studygroup found that ultrasound abnormalities in enthesis are present in a high proportion of patients with IBD, with no signs or clinical symptoms of SpA [36]. Out of the 81 patients, $71(92.6 \%)$ presented almost a tendon disorder that included increased thickness, enthesophytosis, bursitis, and erosions. However, the power Doppler was only positive in $13 / 81(16 \%)$ of the patients. Moreover, enthesopathy as identified by ultrasound, was not associated with the activity, the duration or the type of intestinal disease.

Notwithstanding the fact that our radiographic progression model (Table 5) resulted in a not very high value of $60 \%$, it isn't neglectable either; the model is better able to identify the presence of sacroiliitis when it is indeed present, rather than not identifying the presence of sacroiliitis when in fact it is not present. 
One of the downsides to be acknowledged with regards to this paper is the failure to contrast biomarkers against a control group, recognizing that several biomarkers such as ASCA and Lactoferrin may actually be present in other pathologies different from IBD; i.e., colon and rectal cancer, celiac disease, irritable colon and microscopic cholangitis [37-39].

\section{Conclusion}

The current diagnostic approach based on the clinic, endoscopy, histology, radiology and on biochemical criteria, provides a reliable diagnosis in most cases with IBD, as well as the differentiation among the different subtypes: however, many of these patients are not referred to the rheumatologist because their primary complaint is chronic diarrhea and many of the symptoms overlap with the gastrointestinal condition (arthralgias or enthesitis) [40-42]. Furthermore, the use of DC-ART and other biological therapies may suppress pain but not inflammation and the natural history of the disease, leading to the development of syndesmophytes and/or sacroiliitis which disable the patient for life $[43,44]$. The study of new biomarkers as an additional tool for the clinician will help us to differentiate those patients that should be referred to the rheumatologist and decide in which cases should other therapies be associated to avoid the development of enteropathic arthritis (EnA).

\section{Acknowledgement}

- Professor Adelmo Fernández. Professor of Statistics at UNIMET and UCAB

- Esther Guzmán, BA and Elena Flores, BA, from our immune-rheumatology laboratory at $\mathrm{HUC} / \mathrm{UCV}$

- Dr. Celice Fernández and Dr. Emma Rodríguez, radiologists of the HUC/UCV.

\section{References}

1. Bossuyt $X$. Serologic markers in inflammatory bowel disease. Clin Chem. 2006; 52: 171-181.

PubMed: https://www.ncbi.nlm.nih.gov/pubmed/16339302

2. Sandborn WJ. Serologic markers in inflammatory bowel disease: state of the art. Rev Gastroenterol Disord. 2004; 4: 167-174.

3. Prideaux L, De Cruz P, Ng SC, Kamm MA. Serological antibodies in infl ammatory bowel disease: a systematic review. Infl amm Bowel Dis. 2012; 18: 1340-1355.

PubMed: https://www.ncbi.nlm.nih.gov/pubmed/22069240

4. Abadi I, Gonzalez L, Paul H, Grases P, Pérez G, et al. Silent colonic findings in seronegative spondyloarthropathies. Rev Rheumat. 1981; 11: 119 .

5. Dougados M, Van der Linden S, Juhlin R, Huitfeldt B, Amor B, et al. The European Spondylarthropathy Study Group preliminary criteria for the classification of spondylarthropathy. Arthritis Rheum. 1991; 34: 1218-1227.

6. Saxon A, Shanahan F, Landers C, Ganz T, Targan S. A distinct subset of antineutrophil cytoplasmic antibodies is associated with inflammatory bowel disease. J Allergy Clin Immunol. 1990; 86: 202-210.

PubMed: https://www.ncbi.nlm.nih.gov/pubmed/2200820

7. Rump JA, Scholmerich J, Gross V, Roth M, Helfesrieder R, et al. A new type of perinuclear anti-neutrophil cytoplasmic antibody (p-ANCA) in active ulcerative colitis but not in Crohn's disease. Immunobiology. 1990; 181: 406-413.

PubMed: https://www.ncbi.nlm.nih.gov/pubmed/2099908

8. Zhou G, Song $Y$, Yang W, Guo Y, Fang L, et al. ASCA, ANCA, ALCA and Many More: Are They Useful in the Diagnosis of Inflammatory Bowel Disease?. Dig Dis. 2016; 34: 90-97.

9. Homsak E, Micetic-Turk D, Bozic B. Autoantibodies pANCA, GAB and $P A B$ in infl ammatory bowel disease: prevalence, characteristics and diagnostic value. Wien Klin Wochenschr. 2010; 122(Suppl 2): 19-25. PubMed: https://www.ncbi.nlm.nih.gov/pubmed/20517666

10. Rudwaleit M, Baeten D. Ankylosing spondylitis and bowel disease. Best Pract Res Clin Rheumatol. 2006; 20: 451-471.

PubMed: https://www.ncbi.nlm.nih.gov/pubmed/16777576

11. Austin GL, Herfarth $\mathrm{HH}$, Sandler RS. A critical evaluation of serologic markers for inflammatory bowel disease. Clin Gastroenterol Hepatol. 2007; 5: 545-547.

PubMed: https://www.ncbi.nlm.nih.gov/pubmed/17433787

12. Desplat-Jégo S, Johanet C, Escande A, Goetz J, Fabien N, et al. Update on anti-Saccharomyces cerevisiae antibodies, anti-nuclear associated anti-neutrophil antibodies and antibodies to exocrine pancreas detected by indirect immunofluorescence as biomarkers in chronic inflammatory bowel diseases: Results of a multicenter study, World J Gastroenterol. 2007; 13: 2312-2318.

PubMed: https://www.ncbi.nlm.nih.gov/pubmed/17511029

13. Austin GL, Shaheen NJ, Sandler RS. Positive and negative predictive values: Use of inflammatory bowel disease serologic markers. Am J Gastroenterol. 2006; 101: 413-416.

PubMed: https://www.ncbi.nlm.nih.gov/pubmed/16542272

14. Mendoza JL, Abreu MT. Biological markers in inflamatory bowel disease: Practical consideration for clinicians. Gastroenterol Clin Biol. 2009; 33(Suppl 3): S158-173.

PubMed: https://www.ncbi.nlm.nih.gov/pubmed/20117339

15. Reumaux D, Sendid B, Poulain D, Duthilleul $P$, Dewit $O$, et al. Serological markers in inflammatory bowel diseases. Best Pract Res Clin Gastroenterol. 2003; 17: 19-35.

PubMed: https://www.ncbi.nlm.nih.gov/pmc/articles/PMC3900099/

16. Danese S, Papa A, Saibeni S, Repici A, Malesci A, et al. Inflammation and coagulation in inflammatory bowel disease: The clot thickens. Am J Gastroenterol. 2007; 102: 174-186.

PubMed: https://www.ncbi.nlm.nih.gov/pubmed/17100967

17. Paredes JM, Barrachina MM, Roman J, Moreno-Osset E. Patología articular en la enfermedad inflamatoria intestinal. Gastroenterol Hepatol. 2005; 28: 240-249.

18. Danese S, Semeraro S, Papa A, Roberto I, Scaldaferri F, et al. Extraintestinal manifestations in inflammatory bowel disease. World J Gastroenterol. 2005; 11: 7227-7236.

PubMed: https://www.ncbi.nlm.nih.gov/pubmed/16437620

19. Aydin SZ, Maksymowych WP, Bennett AN, McGonagle D, Emery P, et al. Validation of the ASAS criteria and definition of a positive MRI of the sacroiliac joint in an inception cohort of axial spondyloarthritis followed up for 8 years. Ann Rheum Dis. 2012; 71: 56-60. PubMed: https://www.ncbi.nlm.nih.gov/pubmed/21900284

20. Weber U, Lambert RGW, Østergaard M, Hodler J, Pedersen SJ, et al. The diagnostic utility of magnetic resonance imaging in spondyloarthritis. An international multicenter evaluation of one 
hundred eighty-seven subjects. Arthritis Rheum. 2010; 62: 3048-3058. PubMed: https://www.ncbi.nlm.nih.gov/pubmed/20496416

21. Conigliaro $P$., et al. Impact of a multidisciplinary approach in enteropathic spondyloarthritis patients. Autoimmunity Reviews. 2016; 15: $184-90$.

22. Gutierrez-Gonzalez LA, Nuñez-Sotelo CM, Gonzalez N, Losada BR. High level CTx-II in early Spondyloarthritis patients. Rev Argent Reumatol. 2007; 18: 2.

23. Sarzi-Puttini, Ardizzone S, Manzionna G, et al. Infliximab-induced lupus in Crohn's disease: a case report. Dig Liver Dis. 2003; 35: 814-817. PubMed: https://www.ncbi.nlm.nih.gov/pubmed/14674674

24. Hanauer SB, Feagan BG, Lichtenstein GR, Mayer LF, Schreiber S, et al. ACCENT I Study Group. Maintenance infliximab for Crohn's disease: the ACCENT I randomised trial. Lancet. 2002; 35: 1541-1549.

PubMed: https://pubmed.ncbi.nlm.nih.gov/12047962

25. Hanauer S, Sandborn W, Rutgeerts P, Fedorak RN, Lukas M, et al. Human anti-tumor necrosis factor monoclonal antibody (adalimumab) in Crohn's disease: the CLASSIC-I trial. Gastroenterology. 2006; 130 : 323-333.

PubMed: https://www.ncbi.nlm.nih.gov/pubmed/16472588

26. Rutgeerts $\mathrm{P}$, Sandborn WJ, Feagan BG, et al. Infliximab for induction and maintenance therapy for ulcerative colitis. N Engl J Med. 2005; 353: 2462-2476.

PubMed: https://pubmed.ncbi.nlm.nih.gov/16339095

27. Sandborn WJ, Feagan BG, Stoinov S, Honiball PJ, et al. PRECISE 1 Study Investigators. Certolizumab pegol for the treatment of Crohn's disease. N Engl J Med. 2007; 357: 228-238.

PubMed: https://www.ncbi.nlm.nih.gov/pubmed/17634458

28. Kolho KL, Raivio T, Lindahl H, Savilahti E. Fecal calprotectin remains high during glucocorticoid therapy in children with inflammatory bowel disease. Scand J Gastroenterol. 2006; 41: 720-725.

PubMed: https://www.ncbi.nlm.nih.gov/pubmed/16716972

29. Bonnin Tomás A, Vila Vidal M, Rosell Camps A. Calprotectina fecal como marcador diferencial entre patología gastrointestinal orgánica y funcional. Rev Esp Enferm Dig. 2007; 99: 689-693.

30. Arai R. Serologic markers: impact on early diagnosis and disease stratification in infl ammatory bowel disease. Postgrad Med. 2010; 122: $177-185$

PubMed: https://www.ncbi.nlm.nih.gov/pubmed/20675980

31. Riis L, Vind I, Vermeire S, Wolters F, Katsanos K, Politi $P$, et al. The prevalence of genetic and serologic markers in an unselected European population-based cohort of IBD patients. Infl amm Bowel Dis. 2007; 13: 24-32.

PubMed: https://www.ncbi.nlm.nih.gov/pubmed/17206636
32. Grzybowska-Chlebowczyk U, Wos H, Sieron AL, Wiecek S, Augusciak-Duma A, et al. Serologic investigation in children with infl ammatory bowel disease and food allergy. Mediators Inflamm. 2009; 5126195.

PubMed: https://www.ncbi.nlm.nih.gov/pmc/articles/PMC2796464/

33. Basta Z, Csi I, Szabo G, Szegedi G. Seroreactovity against Saccharomyces cerevisiae in patients with Crohn's disease and celiac disease. World J Gastroenterol. 2003; 9: 2380-2412. PubMed: https://www.ncbi.nlm.nih.gov/pmc/articles/PMC4656483/

34. Eriksson C, Engstrand S, Sundqvist KG, Rantapää-Dahlqvist S, et al Autoantibody formation in patients with rheumatoid arthritis treated with anti-TNF. Ann Rheum Dis. 2005; 64: 403-407. PubMed: https://www.ncbi.nlm.nih.gov/pubmed/15297281

35. Nakamura RM, Matsutani M, Barry M. Advances in clinical laboratory tests for inflammatory bowel disease. Clin Chim Acta. 2003; 335: 9-20. PubMed: https://www.ncbi.nlm.nih.gov/pubmed/12927679

36. Picchianti-Diamanti A, Lorenzetti R, Chimenti MS, Luchetti MM, Conigliaro $\mathrm{P}$, et al. Hepatosplenic T-cell lymphoma in a patient with Crohn's disease. Nat Rev Gastroenterol Hepatol. 2009; 6: 433-436. PubMed: https://www.ncbi.nlm.nih.gov/pubmed/19575026

37. Beigel F, Jürgens M, Tillack C, Subklewe M, Mayr D, et al. Hepatosplenic T-cell lymphoma in a patient with Crohn's disease. Nat Rev Gastroenterol Hepatol. 2009; 6: 433-436. PubMed: https://www.ncbi.nlm.nih.gov/pubmed/19575026

38. Talwalkar JA, Lindor KD. Primary sclerosing cholangitis. Inflamm Bowel Dis. 2005; 11: 62-72. PubMed: https://www.ncbi.nlm.nih.gov/pubmed/15674115

39. García-Planella E, Domènech E. Osteopenia y osteoporosis en la enfermedad inflamatoria intestinal. Gastroenterol Hepatol. 2004; 27: 417-424.

40. Mintz R, Feller ER, Bahr RL, Shah SA. Ocular manifestations of inflammatory bowel disease. Inflamm Bowel Dis. 2004; 10: 135-139. PubMed: https://pubmed.ncbi.nlm.nih.gov/15168814

41. Rothfuss KS, Stange EF, Herrlinger KR. Extraintestinal manifestations and complications in inflammatory bowel diseases. World J Gastroenterol. 2006; 12: 4819- 4831.

PubMed: https://pubmed.ncbi.nlm.nih.gov/16937463

42. Storch I, Sachar D, Katz S. Pulmonary manifestations of inflammatory bowel disease. Inflamm Bowel Dis. 2003; 9: 104-115. PubMed: https://pubmed.ncbi.nlm.nih.gov/12769444

43. Trost LB, McDonell JK. Important cutaneous manifestations of inflammatory bowel disease. Postgrad Med J. 2005; 81: 580-585. PubMed: https://www.ncbi.nlm.nih.gov/pubmed/16143688

44. Tsianos EV, Katsanos K. Do we really understand what immunological disturbances in inflammatory bowel disease mean? World J Gastroenterol. 2009; 15: 521-555. 102457. 